\title{
PLANEJAMENTO PARTICIPATIVO: UMA ESTRATÉGIA POLÍTICA E EDUCACIONAL PARA O DESENVOLVIMENTO LOCAL SUSTENTÁVEL (RELATO DE EXPERIÊNCIA DO PROGRAMA COMUNIDADE ATIVA)
}

\author{
Ludmila Oliveira Holanda Cavalcante* \\ Luiz ANTÔNio Ferraro JúNior**
}

RESUMO: O presente artigo trata da descrição analítica do programa de intervenção Comunidade Ativa no semi-árido baiano, a partir da realização dos processos de capacitação de Fóruns dos municípios integrantes do Programa Faz Cidadão. Objetivamos, com este estudo, discutir a proposta metodológica do trabalho, a operacionalização do Programa e a sobrevivência dos Fóruns locais dentro dos princípios conceituais de sustentabilidade. Tais programas governamentais pretendem estimular a constituição e capacitação de espaços de locução e negociação (Fóruns), representativos de comunidades com baixo IDH, que possam contemplar peculiaridades locais, na construção de processos educacionais emancipatórios para o Desenvolvimento Local Integrado e Sustentável (DLIS). Apesar desta clareza de propósitos, nem sempre ocorre uma sinergia nas ações das esferas do poder público e da comunidade. A estratégia política e educacional do planejamento participativo deve, portanto, ser pensada e construída de modo a articular, efetivamente, as ações dos diferentes parceiros. As potencialidades de transformação de tais processos de intervenção são tão significativas quanto os problemas que devem enfrentar. $\mathrm{O}$ não enfrentamento das dificuldades pode, na ação de qualquer um dos parceiros, inocente ou intencionalmente, significar a manutenção do status quo através de uma proposta de transformação.

Palavras-chave: Planejamento. Participação. Representação. Educação. Locução. Enunciações. Conscientização. Emancipação. Sustentabilidade. Comunidade. DLIS.

\footnotetext{
* Professora Assistente do Departamento de Educação da Universidade Estadual de Feira de Santana (UEFS).E-mail: ludmilaholanda@yahoo.com

** Professor Assitente do Departamento de Tecnologia da UEFs. E-mail: luizferraro@hotmail.com
} 


\section{Participatory PLANNING: A POLITICAL AND EDUCATIONAL STRATEGY for an INTegrated, Local Sustainable Development}

ABSTRACT: This paper describes and analyses a governmental development program called "Comunidade Ativa" in its "Programa Faz Cidadão" version, designed for Bahia's arid inlands. Through the concepts of sustainability, it discusses its proposals for community leadership training courses and analyzes its methodological approach, its working procedures and the survival of its community fora. Such governmental programs intend to stimulate the constitution and ability of negotiation in representatives of communities with a low $\mathrm{Hu}$ man Development Index (HDI), taking local peculiarities into account while constructing an emancipating educational process, in order to attain an Integrated, Local Sustainable Development (ILSD). These clear proposals nevertheless, do not seem to entail effectiveness nor synergy between the government and local communities' actions. The political and educational strategy of participatory planning should therefore consider articulating the actions of different partners. The transformation potentialities of such intervention processes are as significant as the problems they are supposed to overcome. Thus, if difficulties are not properly faced by all the parts involved, this program could paradoxically lead to maintaining the status quo through a transformation proposal.

Key words: Planning. Participation. Representation. Education. Elocution. Enonciations, awareness building. Emancipation. Sustainability. Community. ILSD.

\section{Introdução}

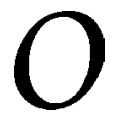

Programa Faz Cidadão é a versão estadual da proposta do Comunidade Ativa, programa do Governo Federal que tem por princípio a organização comunitária no processo de análise e compreensão da realidade local, visando o Desenvolvimento Local Integrado e Sustentável (DLIS) de municípios com baixo Índice de Desenvolvimento Humano (IDH). A proposta difere, em princípio, das convencionais intervençōes comunitárias governamentais por não dar um enfoque exclusivamente econômico à perspectiva de desenvolvimento e por acreditar que para alcançar a sustentabilidade é necessário focalizar-se nas diversas dimensóes (cultural, econômica, política, social, histórica, ambiental...) da realidade local. "Inova" também por dividir responsabilidades e buscar parcerias com a comunidade local, organizações da sociedade civil, o setor privado e poderes públicos municipal, estadual e federal. 
A palavra "sustentabilidade" tem forte conotação valorativa: reflete mais uma expressão dos desejos e valores de quem a exprime do que algo concreto, de aceitação geral. Em razão disso, as definições correntes são vagas e amplas o suficiente para englobar o máximo de condições que se possam requerer do processo de desenvolvimento (Cunha, 1994).

Segundo Trigo et al. (1994), o conceito de sustentabilidade implica uma perspectiva, um critério geral no que se refere às relações básicas da organização social, mais do que um conjunto concreto e específico de açôes a serem empreendidas por indivíduos ou organizações públicas e privadas de uma sociedade em particular.

O conceito de sustentabilidade, que vem sendo desenvolvido nos últimos 30 anos, só começou a se consolidar como proposta objetiva de transformação da sociedade a partir do encontro da "Rio92" e do relatório da comissão Brundtland, para a qual o "Desenvolvimento sustentável procura satisfazer as necessidades do presente sem comprometer a capacidade das gerações futuras alcançarem suas próprias necessidades."

No Brasil, duas metodologias fundamentadas no conceito de Desenvolvimento Sustentável (DS), vêm sendo largamente divulgadas e implementadas. A primeira é conhecida como Agenda 21, uma estratégia de desenvolvimento sustentável que vem sendo desenvolvida pelo Ministério do Meio Ambiente (MMA) através da Comissão de Políticas de Desenvolvimento Sustentável e da Agenda 21 para o país, e incentivada nos níveis estadual e municipal, separadamente. Cada esfera reúne seus representantes para planejar ações para o desenvolvimento sustentável. Em nível nacional a agenda foi dividida em seis dimensões: Gestão dos Recursos Naturais; Agricultura Sustentável; Cidades Sustentáveis; Infra-estrutura e Integração Regional; Redução das Desigualdades Sociais e Ciência e Tecnologia.

A outra estratégia é conhecida como DLIs (Desenvolvimento Local Integrado e Sustentável), expressão utilizada desde 1997 e que foi lançada institucionalmente pelo Conselho da Comunidade Solidária e defende cinco objetivos básicos, segundo um de seus principais teóricos, Franco (2000): 1) Superar a pobreza; 2) articular desenvolvimento econômico ao humano e social; 3) constituir-se em uma estratégia contra-hegemônica do processo de globalização; 4) ser uma estratégia para a sustentabilidade; 5) transformar a sociedade rumo à democracia, cidadania e sustentabilidade. 
Em 1992, enquanto os governos articulavam a proposta de Agenda 21 e Desenvolvimento Sustentável, os representantes das ONGS e movimentos sociais criticaram-na e desenvolveram o "Tratado de Educação Ambiental para Sociedades Sustentáveis (ss) e Responsabilidade Global". O tratado constitui-se de uma carta de princípios e um plano de açôes. Grosseiramente, podemos interpretar que a maior discordância entre as propostas de DS e ss esteja no fato da segunda contestar categoricamente a idéia de desenvolvimento como um caminho positivista e hegemônico pelo qual todas as comunidades devam passar e se integrar para se incluir na sociedade globalizada economicamente. Os conceitos de sócio-diversidade e diversidade cultural fazem efetivamente parte da proposta de Sociedades Sustentáveis na busca de uma sociedade global multifacetada, sustentável e includente, não apenas no sentido econômico; em termos de metodologia os princípios da proposta fazem emergir idéias como representaçôes sociais, sujeito coletivo, emancipação política, econômica e cultural e redes de sustentabilidade e solidariedade.

O termo "Local", aplicado pelos teóricos do programa Comunidade Ativa ao conceito de Desenvolvimento Sustentável, talvez seja uma tentativa destes de se aproximar da proposta de Sociedades Sustentáveis demonstrando, ao menos no conceito, uma busca pela particularização do processo de construção da sustentabilidade e de respeito às peculiaridades do local, mesmo que esta busca ainda se denomine "desenvolvimento".

A proposta deste texto é analisar as estratégias educacionais da metodologia DLIs à luz das práticas realizadas em cinco municípios baianos, assim como seu potencial político de transformação da(s) sociedade(s).

Ao definir a estratégia de DLIS, o documento do Programa Faz Cidadão do governo do estado da Bahia para a comunidade complementa: "Enfim, o Faz Cidadão baseia-se na convergência da oferta estatal de programas e obras, articulada nos três níveis de governo, na transformação das demandas privadas em demanda social pública e na articulação da oferta estatal disponível com a demanda social dos municípios em questão". O que nos leva a concluir que, de certa forma, já há, nesta interpretação, uma redução do espectro da proposta do programa DLIS para seu similar baiano.

Provavelmente, por ser uma proposta governamental nos níveis federal, estadual e municipal, o trabalho passa por diversos momentos 
de intervenção no local e é construído de forma que vários agentes participem de todo o processo de acesso e divulgação do trabalho. $\mathrm{O}$ momento inicial do programa fica ao cargo de altas instâncias do governo estadual, que através de seus parceiros apresentam a proposta inicial e fazem os primeiros contatos para a seleção dos membros do Fórum do município.

O papel do Fórum é de grande importância, é através dele que o trabalho enraíza-se na comunidade. Com um número que varia entre 30 e 40 integrantes, o Fórum passa a ser o ponto de conexão entre o trabalho desenvolvido durante o processo de capacitação do Faz Cidadão e a população local. Dessa forma, faz-se necessário que o Fórum seja composto por lideranças locais e representantes de toda a comunidade; é fundamental que este transforme-se em uma instância autônoma, que garanta a continuidade do trabalho após a intervenção técnica no município.

O processo de seleção e triagem do mesmo acontece nos momentos iniciais do programa (Sensibilização), quando os órgãos parceiros vão tentando contatar grupos, associações, igrejas, poder legislativo, sindicatos e segmentos representativos não organizados da comunidade, com o objetivo de divulgar a proposta e seus objetivos para com isso conseguir a adesão destas instâncias ao programa.

Identificadas e sensibilizadas, de acordo com essa orientação, o grupo da comunidade passa então a compor o Fórum, que já formado estará "pronto" para fazer parte do momento de Capacitação do programa Faz Cidadão.

A Capacitação do Fórum visa a formação de habilidades e competências para a construção de um processo de Planejamento Participativo que, por sua vez, deve resultar na elaboração do Plano de Desenvolvimento Local Integrado e Sustentável (PDLIS); este é o documento base para a implementação das ações definidas pela população em prol do desenvolvimento do seu município. Para este fim, o governo estadual da Bahia, através da Fundação Luís Eduardo Magalhães (FLEM), buscou a construção de uma parceria com as universidades estaduais, que se encarregam de contatar o Fórum e, com uma proposta de trabalho in loco de cerca de 80 horas distribuídas ao longo de dez dias, a equipe de professores da universidade realiza a etapa da capacitação ${ }^{1}$ para a construção do Plano e preparação do grupo para as negociações que se seguirão. 
A equipe técnica da universidade é composta por professores com formaçôes diversas como pedagogia, engenharia agronômica, história, administração, sociologia e economia, com mestrado e/ou especializaçōes, com uma boa experiência de trabalho em comunidade e em projetos de pesquisa e extensão. Os técnicos também participaram de um processo de formação para atuar no programa através de oficinas com consultores governamentais, como também de um curso a distância de cerca de 132 horas, promovido pela PUC de Minas Gerais e a Agência de Educação para o Desenvolvimento (AED), sob orientação do Programa Comunidade Ativa. O objetivo de tal processo de Capacitação para capacitadores era o de, entre outras coisas, unificar uma abordagem conceitual e metodológica em torno da proposta do Governo Federal.

Além dos professores, a equipe conta também com um significativo apoio de estudantes da própria instituição, que, no papel de estagiários, desenvolvem um trabalho de pesquisa e atuação durante e depois da Capacitação, auxiliando também no registro da mesma.

\section{Abordagem metodológica}

"Que bonito, contou a história sem letra!"

(Sr. Antonio, membro do Fórum, município D)

A nossa equipe, em particular, trabalhou com o processo de capacitação de cinco Fóruns municipais ao longo de oito meses, todos eles no estado da Bahia, mas com inúmeras peculiaridades relacionadas à história e a cada regiáo na qual estavam inseridos. Esses foram os nossos primeiros municípios sob a orientação da proposta do Faz Cidadão e, apesar das experiências anteriores com trabalhos comunitários, podemos afirmar que a cada Fórum que trabalhávamos, aprendíamos algo que não sabíamos anteriormente. A percepção do processo de construção do conhecimento nesta experiência é cada vez mais nítida e é fundamental que se reconheça a importância desta troca de informaçōes e reflexōes entre mundos, linguagens e perspectivas tão diversas. Enquanto professores (de universidade, sobretudo), acreditamos ser esta uma oportunidade única de reavaliar nossas práticas, conceitos, açôes e dogmas acadêmicos, que muitas vezes, no vício da instituição universitária, pouco se confrontam com a realidade, que constrói suas próprias teorias e valores e que delas sobrevivem. A experiência com comunidades (rurais principalmente) nos alerta para 
a riqueza de cada espaço e cultura e nos remete a histórias que muitas vezes não têm registro em livros, sai das vozes, das memórias, das conversas com o outro. Nosso trabalho começa daí, da valorização destas memórias, da busca por esses discursos pouco escutados e valorizados, do apoio à construção da história local por sua própria gente e da possibilidade de construção do futuro que aspiram e que podem/ querem ajudar a construir.

De acordo com a proposta governamental, a Capacitação passaria por apenas três etapas de trabalho no município: o Diagnóstico Estratégico, a elaboração do Plano de Desenvolvimento Local Integrado e Sustentável (PDLIS) e da Agenda de Prioridades Locais e a terceira, que seria a socialização do PDLIS para o Fórum.

A nossa equipe de trabalho, ao longo de um processo de reformulação da proposta inicial, reorganizou a carga horária, na medida do possível, por acreditar que a mesma não era compatível com um trabalho tão politicamente significativo para a comunidade local. Adequar o tempo é um aspecto relevante em um processo de capacitação que vise, entre outras coisas, a elaboração de um planejamento estratégico participativo de um local, e a experiência estava evidenciando que, para chegarmos ao nível necessário de reflexão e compreensão da dimensão política deste encontro, o Fórum necessitaria de uma dinâmica de trabalho muito mais complexa e intensiva do que a inicialmente proposta. Além disto, por haver a clara orientação governamental de que a capacitação tem como função apresentar um produto (o PDLIS), corria-se o risco de se valorizar demasiadamente a elaboração do documento em detrimento de se realizar um trabalho voltado para a construção de um Fórum autônomo e politicamente representativo no Município. Assim, com a distribuição do tempo minimamente transformada, fomos também modificando alguns "dogmas" metodológicos por acreditar que, ao planejar, devemos em primeira instância levar em consideração as pessoas que estarão envolvidas no trabalho e, dessa forma, à medida que íamos conhecendo o Fórum e o local, íamos construindo abordagens metodológicas que conseguiam adequar-se ao contexto e trazer os resultados esperados de forma mais efetiva e prazerosa.

A busca pela autonomia na construção deste trabalho é, para esta equipe, mais que um ornamento conceitual, um dentre outros, é a própria razão de ser do trabalho; sem esta busca escreve-se, no máximo, um bom documento, mas desperdiça-se um espaço de locução cheio de potencial para alavancar a emancipação da comunidade. A função 
da autonomia, para Guattari (2000), não é a de um simples grau de tolerância para adoçar o centralismo com uma dose de autonomia, é antes disso a de captar todos os impulsos de desejo, todas as inteligências, não para fazê-las convergir em um mesmo ponto central arborescente, mas para dispô-las em um mesmo rizoma, que atravessará todas as problemáticas sociais, tanto a nível local, quanto regional, nacional e internacional.

Dividimos o trabalho em 4 etapas de intervenção in loco: na primeira etapa, em apenas um dia de contato com o Fórum, chamado de "Viagem Precursora", onde re-apresentamos a proposta Faz Cidadão, nos apresentamos e conhecemos o Fórum enquanto grupo. Neste momento, discutimos a questão da representatividade, ${ }^{2}$ conceito fundamental na compreensão do trabalho que se inicia e ponto-chave do processo de formação e capacitação do Fórum. Para trazer o conceito para a prática do fórum realizamos um "Diagnóstico Participativo da Representatividade" com os membros presentes. Neste, identificamos segmentos, localidades, dimensões, instituições e organizações da sociedade civil e do estado para avaliar o quanto estas estão representadas naquele grupo. Neste contato também negociamos o calendário para as etapas seguintes e procuramos conhecer, ainda que de forma superficial, um pouco da estruturação inicial do Fórum, do município e de seu contexto. A negociação do calendário é um treino para o diálogo, o dissenso e a tomada de decisões em grupo, além de demonstrar claramente a abertura e a base dialógica que nordestearão ${ }^{3}$ as relações técnicos-grupo.

A segunda etapa do trabalho consiste em 3 dias no município, quando a equipe começa de fato o processo de Capacitação. Neste momento, o Fórum é orientado a buscar as referências históricas do município e passa a construir a história local a partir de discursos, depoimentos da comunidade e referências de registros e documentos locais. Além de ser um momento significativo para os membros do Fórum por "resgatar" dados e estórias relacionadas às suas vidas, é também importante como um momento indicador do grau de topofilia existente no grupo, por demonstrar muitas vezes o nível de afinidade e identidade cultural com o local em que vivem e por denunciar, muitas vezes, o nível de entusiasmo ou apatia diante desta história. Os sujeitos coletivos emergem quando um agrupamento de pessoas se reconhece na história comum e/ou na percepção de que partilham um mesmo destino (Bosi, 1987). A partir desta hipótese passamos a nos dedicar, tempo e esforço, para fazer o melhor registro e síntese possíveis das 
diversas histórias. Outro aspecto interessante neste processo de "resgate" da história local é que marca o início de um trabalho voltado para a participação e envolvimento do Fórum diante de discussōes importantes para a realização do planejamento do município; é com a realização desta etapa que o Fórum vai compreendendo a forma de trabalho utilizada em todo processo de capacitação. Ainda nesta segunda etapa, denominada "Diagnóstico Estratégico", os membros, organizados em grupos de trabalho, levantam aspectos importantes da realidade dividida, didaticamente, em sete dimensōes: 1) Organização Social; 2) Economia e Renda; 3) Saúde; 4) Educação; 5) Infra-estrutura e Meio Ambiente; 6) População, Cultura, Esporte e Lazer; 7) Finanças públicas. Esta divisão segue utilizada até o final da capacitação; cabe ressaltar que a função é didática e sem esta divisão não seria possível organizar o trabalho de diagnóstico e planejamento participativo.

Levantadas as características de cada setor, desenvolvemos a conceituação e a metodologia necessárias para transformar o conjunto de informaçôes em um diagnóstico estratégico. No diagnóstico estratégico as informaçôes de cada setor são avaliadas como sendo externas ou internas; os dados externos são classificados como oportunidades ou ameaças, os internos como pontos fortes ou pontos fracos. Consolidados os sete painéis com os dados já avaliados dentro desta perspectiva qualitativa, levantamos, com o fórum, novas informaçōes externas ou internas, positivas ou negativas. Apesar desta divisão didática em dimensões da realidade, as discussōes em torno de cada tópico vão permitindo que o grupo visualize não um enorme conjunto de problemas e aspectos, mas algumas problemáticas, entendido como um conjunto articulado e intrincado de problemas.

A terceira etapa fundamenta-se no produto gerado na segunda, ou seja, o diagnóstico estratégico. Esta etapa centra-se na elaboração do PDLIS, Plano de Desenvolvimento Local Integrado e Sustentável, e por significar um momento de fundamental importância no processo de capacitação, estamos continuamente avaliando nossa abordagem metodológica, por admitir que existem peculiaridades locais que determinam certos comportamentos e reações em cada Fórum e que merecem algumas considerações.

Apesar da indicação de uma metodologia única por parte de todos os técnicos envolvidos no Programa Faz Cidadão, a existência inegável da peculiaridade do "local" requer, quase sempre, uma adaptação e análise de todo o processo de planejamento definido, de acordo com a realidade e contex- 
to no qual estamos inseridos e deveremos trabalhar. A comunidade ali representada trazia em seu discurso uma fragilidade e resistência na compreensão de conceitos como organização política, representatividade, identidade e união. A comunidade local é historicamente reconhecida como um grupo de pessoas com pouca vivência de articulação política e que, embora consciente de seus problemas, não demonstrava muito interesse ou entusiasmo para tentar resolvê-los ou amenizá-los. (...) Havia o senso de "dever" ao participar do Fórum, mas não captávamos o "desejo" de construir um momento significativo para o processo de desenvolvimento local. (Relatório Analítico do município C)

De acordo com o trabalho realizado na etapa anterior, o grupo já tem a clara noção das dificuldades enfrentadas pela comunidade e município em geral, assim como uma enunciação do que vislumbram para a construção de um local com melhor qualidade de vida. Através de questôes problematizadoras e jogos interativos, o Fórum expõe de diversas formas os sonhos, anseios e desejos da coletividade em momentos que são permeados de significados (sociais) e sentidos (pessoais) para todo o grupo. Esta é a segunda estratégia para fortalecer a construção de um sujeito coletivo, fundamentada na percepção de que partilham, em função de tendências impostas pela realidade, de um destino comum e talvez partilhem também de sonhos comuns que podem permitir-lhes visualizar a possibilidade de se unirem para reverter tendências indesejadas.

Realizamos a Dinâmica do "O município que temos e o município que queremos" - (...) esta dinâmica tem sido muito importante no nosso trabalho, pois é a partir dela (do lúdico) que muitos dos problemas e muitos dos anseios da comunidade são colocados para a plenária, é através destes cartazes que o fórum as vezes consegue dizer o que não disse em outros momentos. Nos cartazes eles falam da realidade com muita naturalidade e através dele projetam sonhos que antes ficavam mais difíceis de serem verbalizados. (Relatório Analítico do município de B)

Além destas enunciaçôes, procuramos garantir momentos outros que trouxessem um processo de discussão e análise deste contexto social, assim como uma reflexão que antecedesse e compreendesse o planejamento como um processo ininterrupto de pensar o local, seus problemas e possibilidades. Com um "Diagrama Prospectivo de Análise de Processos" (DPAP), uma variação do Diagrama de Ishikawa, por exemplo, o Fórum se via diante de um processo de reflexão sobre a origem, conseqüências e encaminhamentos dos seus problemas que permitiam uma compreensão estrutural de cada um deles e conseguiam, 
através de uma abordagem construtivista, denunciar a complexidade da realidade local e a vinculação da mesma com realidade outras, que rodeiam seu cotidiano. Esta atividade busca garantir a percepção das problemáticas, ou seja, a articulação de causas que condicionam a situação vista como indesejável.

O Fórum mostrou-se um pouco ansioso com a proposta de trabalho com o Diagrama, mas ao se reunirem em seus subgrupos (...) e começarem a analisar cada ponto fraco existente nos painéis, foram progressivamente desenvolvendo um processo de discussão e reflexão em torno de cada problema ali ilustrado e bem conhecido pela comunidade, que chegou a um nível de envolvimento que surpreendeu a equipe. As noçōes de causa e efeito, as explicaçōes para cada fato e suas conseqüências em tempo e espaço determinados proporcionaram ao Fórum um amadurecimento em torno de problemáticas locais que dificilmente poderíamos conseguir em tempo tão reduzido neste trabalho de Capacitação. O que inicialmente parecia muito difícil e inatingível revelou-se para o grupo um trabalho de enriquecimento da comunidade sobre sua própria realidade e nos fez refletir muito sobre a importância deste trabalho para o local. A reflexão avançou muito na integração entre as diferentes dimensões do desenvolvimento e a inter-relação entre aspectos exógenos e endógenos. (Relatório Analítico, município C)

As ações foram sendo construídas com base nas reflexóes, e as problemáticas do município foram sendo contempladas em nível de possíveis soluções, evitando que a discussão não se perdesse em discursos lamentosos e sem direcionamento e, desta forma, procurávamos garantir a noção de que o trabalho ultrapassasse o processo catártico de "dar voz aos pouco escutados" (Giroux, 1999) e que o Fórum buscasse um encaminhamento para suas angústias coletivas.

Neste momento percebemos, com maior ou menor grau, que houve, ao longo do processo de trabalho, a emergência de um sujeito coletivo, fruto do esforço para aprofundamento da reflexão crítica sobre a realidade e da desideologização do espaço de locução. Em contraposição a isso, ao analisarmos o teor informativo da proposta inicial do processo de Capacitação, percebemos uma significativa pressão por um trabalho de caráter conteúdista e carregado de teor conceitual de noções como desenvolvimento, globalização, parcerias, competividade, mercado local e global... Por estarmos preocupados com a adequação pedagógica ${ }^{4}$ diante do público com o qual iremos trabalhar, fomos buscando algumas formas alternativas para lidar com tais conceitos. As ações que foram sendo elaboradas pelo Fórum, por exemplo, foram sendo escritas em papéis em formas de folhas, e foram 
formando a copa de uma árvore, desenhada no chão que designava a idéia de Desenvolvimento Local Integrado e Sustentável.

Ao utilizar a árvore que deu origem ao nome de um dos municípios, e que está em processo de extinção no local, nós conseguimos demarcar uma discussão que se tornou fundamental na construção cognitiva não só de conceitos, mas de compreensão contextual dos mesmos, proporcionando um processo de construção de conhecimento pautado na percepção de aprendizagem significativa (Matui, 1995).

A árvore seria a representação de " $\mathrm{A}$ "... Sobre a copa dissemos que ela reflete o desenvolvimento de " $A$ ", que cada folha é uma ação e como as folhas devem buscar a energia do sol e que é a saúde destas folhas, seu bom desenvolvimento que permitirá que " $\mathrm{A}$ " se desenvolva. A função da comunidade é fazer com que estas folhas vinguem e mandem energia para a raiz para que a árvore como um todo desenvolva-se e dê frutos. A idéia de que os frutos e folhas que depois de concluídos em seu papel caem e fertilizam a própria árvore foi utilizada para demonstrar a idéia de que o desenvolvimento é um processo cíclico, não-linear, que se retro-alimenta. $\mathrm{O}$ desenvolvimento se observa em toda a copa, através das acôes-folhas, este deve ser equilibrado, a copa não pode pender para qualquer lado. Este desenvolvimento é local, é inerente a " $A$ " ..., não outra árvore. A integração foi um conceito reforçado pelo tronco da árvore, no qual cada setor estava inscrito, todos indissociáveis. A sustentabilidade de todo o processo vem da raiz, que o segura, que o mantém de pé, que utiliza o potencial local, que é a vocação sendo realizada e mantendo as folhas hidratadas e fortes. Sem a hidratação vinda da raiz as folhas perecem e mesmo o sol que é uma oportunidade de ganhar mais força, mais energia, pode tornar-se uma ameaça que castiga a árvore. A idéia toda da árvore do desenvolvimento pareceu terminar de solidificar os conceitos de Duss e reforçaram a idéia de que as ações dependem da comunidade. (Relatório Analítico da Capacitação no Município A.)

A discussão da Vocação é outro ponto complexo da capacitação, a vocação sendo a "raiz" da árvore e, desta forma, é o elemento de foco na proposta de DLIS governamental. A vocação terá um efeito nordesteador para as ações governamentais, que, segundo o discurso do próprio programa, em um espaço de dois anos estará investindo no potencial econômico local, seja ele com foco na agricultura, agropecuária, comércio... na verdade, identificar a vocação do município e registrá-la no Plano através da Agenda de Prioridades é o momento de enunciação do Fórum para as instâncias governamentais “ávidas” por dar um caráter alavancador do trabalho de DLIS. A mensagem do programa é clara, o 
Plano é responsabilidade do Fórum, é através dele que as açōes serão encaminhadas e gerenciadas; quanto à Agenda, que lida com as prioridades para a sedimentação e estruturação da vocação, cabe ao governo assumir boa parte da responsabilidade em função de agilizar a concretização de ações que possibilitem o caminhar econômico do município.

A elaboração da Agenda, que envolve a eleição de um subfórum - uma "equipe gestora” dentro do próprio Fórum, responsável por negociações com o governo - passou a se constituir na quarta etapa do nosso trabalho. Inicialmente, a proposta era de realizar a agenda ao término da elaboração do Plano, o que diante de uma proposta analítica de construção de um planejamento estratégico ficaria completamente inadequado em relação ao tempo, qualidade de trabalho e concretização de resultados. A Agenda, dessa forma, passou a exigir mais um encontro do Fórum com a equipe técnica, que, aproveitando o momento para apresentar a versão preliminar do Plano para o grupo, avaliava o nível de envolvimento com a continuidade do trabalho e retomava as discussões tendo a vocação como ponto de partida.

De início tivemos uma certa dificuldade em conseguir que os integrantes do fórum percebessem que a agenda local deveria estar centralizada em açôes prioritárias que pudessem alavancar o desenvolvimento do município a partir de uma tendência de produção/trabalho predominante entre eles. Muitos sentiam-se confusos para conseguir compreender o sentido de prioridades no contexto macro de demandas ilustradas no PDLIS. Necessidades como a resolução dos problemas de falta de água na sede e as condições de moradia de alguns eram muitas vezes temas polêmicos, pois muitos não se contentavam com o fato de tais demandas não fazerem parte da Agenda Local.

A equipe técnica se deteve na explicação do termo prioridades por diversas vezes, e só depois de um tempo, com uma certa abnegação o fórum conseguiu contemplar a proposta direcionada da Agenda em função de sua vocação. (Trecho do Relatório Analítico de Capacitação do Município B)

Parecia claro para nós que a confusão da compreensão da Agenda como prioridade governamental estava vinculada à insegurança da população com relação ao encaminhamento de todas as outras ações, no seu entender também prioritárias, que estavam fazendo parte do PDLIS e que temiam não serem contempladas nas intervenções oficiais. Muitas das discussóes com a comunidade em torno do significado da Agenda no incentivo ao setor econômico do município pareciam deri- 
var da ansiedade em reconhecer a vocação como potencial de mercado ou não.

Com a elaboração da Agenda e a escolha da equipe gestora, preparada para negociar com as instâncias governamentais e fazendo a conexão entre Fórum e governo, o programa de capacitação finaliza sua intervenção no município acreditando e reafirmando estar o mesmo diante de um trabalho que apenas se inicia. Sendo o conceito de DLIS conhecido e compartilhado pelo grupo, referimo-nos ao mesmo como Fórum DLIS em contraposição ao nome Fórum Faz Cidadão, para desvincular o trabalho do grupo do Programa Governamental, desejando que o mesmo, dentro da perspectiva de autonomia, consiga seguir adiante independentemente das intervenções do governo no local ou da própria manutenção do programa. Reconhecemos, no entanto, que esta é uma preocupação de difícil solução, haja vista todo o caráter propagandista do Programa que quer definitivamente vincular suas ações a um momento governamental demarcado.

Foi interessante perceber o quanto a comunidade inicialmente resistiu à noção de coletividade e representatividade local durante a Capacitação. Existia permanentemente uma atitude paternalista por parte dos membros do Fórum que pareciam interpretar o Programa Faz Cidadão como mais uma proposta governamental que supriria suas necessidades imediatas em tempo hábil e com mínima participação ou envolvimento da sociedade civil. O poder de barganha e negociação neste processo estava sendo subestimado, assim como o poder político da organização comunitária tão bem enfatizado no processo de Capacitação. Acreditamos que só neste momento de elaboração da Agenda que o Fórum passou a ter a noção exata da proposta de compromisso da comunidade no processo de desenvolvimento local, e a partir desta constatação, esperamos que o Fórum passe a valorizar o real significado do seu trabalho para o desenvolvimento de C. (Relatório Analítico de Atividade do Município C)

Ao finalizar o nosso trabalho no município, acreditamos estar diante de várias incógnitas: Será mesmo o Fórum capaz de assumir esta responsabilidade diante do Plano de Desenvolvimento Local? Haverá mesmo uma continuidade do trabalho do Fórum mesmo que as ações governamentais não se concretizem? Haverá mesmo uma representatividade política apartidária em prol do bem coletivo funcionando com autonomia, como uma instância de decisôes políticas paralela às instâncias do estado resultante da organização da sociedade civil? Estará mesmo o governo comprometido com o desencadear destas propostas?... 


\section{Discussões}

Desafios para a concretização do Desenvolvimento Local Integrado e Sustentável: uma reflexão sobre a prática

Diante de todas as inquietações nossas por parte do desencadear deste trabalho, acreditamos que existam inúmeros desafios ao processo de DS que não podem nem devem ser desmerecidos. Tentaremos enumerar alguns:

\section{Os desafios metodológicos para as questões culturais}

$O$ conceito de Desenvolvimento $e$ as diversas leituras de desenvolvimento locais

Quando nos dirigimos a uma comunidade propondo um trabalho de DLIS, há sempre um "gap" entre novos entendimentos e o entendimento da comunidade sobre desenvolvimento, que acreditamos ser historicamente construído e reforçado na nossa cultura colonizada. As expectativas e visōes das pessoas estão condicionadas pela mídia e se relacionam com os padrões globalizados de consumo, como carros, shoppings, VCRS... Tais constatações nos levam a acreditar que:

- Eles, enquanto comunidade, dificilmente atingirão tais padrōes;

- o não atendimento destas expectativas gera uma enorme frustração e uma descrença no processo de DLIs;

- caso este resultado fosse possível, e todas as pequenas comunidades atingissem suas idéias de desenvolvimento, o planeta entraria em colapso ambiental.

As necessidades são, ao mesmo tempo, tão grandes e tão condicionadas que muitas vezes os atores sociais apenas fingem aceitar a proposta de trabalho dentro da ótica de processo, mas o que eles querem (e isso fica bem claro para nós, técnicos), é alcançar resultados... resultados estes que mais parecem kit civilizaçãa (Krenak) do que o mundo todo em um caos ambiental. A pobreza é gerada, em nossa sociedade, não somente pela carência material, mas também muito pela produção de ausências, todos sentimos falta de algo material, independente de quanta matéria temos. 
A pobreza, segundo Tassara (2001), tem duas origens, a carência efetiva da matéria e a produção de ausências, em função da qual sentimonos pobres por não termos o que a sociedade, de forma multimídia, ensina-nos a necessitar.

Este é, certamente, um grande desafio: Como contribuir para a construção local de uma sociedade sustentável quando esta encontra-se submetida, objetiva e subjetivamente, a um conceito hegemônico de desenvolvimento? Como singularizar a construção da sociedade sustentável daquele local? As respostas devem encontrar-se em processos de resgate da auto-estima, da história, do sentimento de pertencimento, da identificação, da topofilia e solidariedade.

Apesar deste descompasso na compreensão de desenvolvimento, a comunidade algumas vezes parece "fingir" aceitar a proposta e seu "discurso" de que o desenvolvimento parte da construção local. Existe, nos parece, um certo medo de perder o que pode significar a "oportunidade" que a eles se apresenta. $\mathrm{Na}$ dúvida eles colaboram, mesmo sem estarem ao certo tão confiantes na proposta, primeiro porque deve haver uma certa pressão do poder local (políticos, cargos de confiança, relações de dependência típicas em comunidades pequenas do interior do nordeste brasileiro); segundo, porque precisam assegurar o momento de participação para que "não percam o bonde da história", o que sem dúvida também está relacionado com as relaçōes de poder do local...

Ontem à noite eu estava em casa pensando: vou ou não vou? O doutor (...) me convidou para fazer parte do fórum, me falou do programa e eu fiquei pensando 'não vou'. Mas aí pensei: 'e se eu não for e esse negócio der certo e eu ficar de fora?' Aí eu vim e estou feliz de tá aqui! (Membro do Fórum do Município E, avaliando a Capacitação)

\section{Desafios metodológicos para os aspectos socioeconômicos}

\section{O foco no incremento de capital social e humano articulado ao capital econômico}

Esta característica de diversos programas e projetos de Desenvolvimento Sustentável parte da premissa ou hipótese de que os diversos locais têm como principal gargalo os aspectos sociais e humanos; outros elementos necessários ao desenvolvimento como capital econômico seriam mobilizados, caso o capital social e o humano fossem incrementados.

Em geral, entende-se por capital social a organização comunitária, potencial para a educação, capacidade de mobilização dos recursos 
humanos, topofilia... enquanto capital humano é tomado pelo conjunto das capacidades humanas individuais de um local, que podem ser mobilizadas para seu desenvolvimento.

Principalmente nos países emergentes, subdesenvolvidos, em desenvolvimento, do Sul, de Terceiro Mundo, ou categoria que os valha, a necessidade de incremento da organização e capacitação local é inegável; assumir o "gap" desses capitais como sério entrave ao desenvolvimento é bastante acertado pela proposta de DS. A questão do foco no âmbito social, político e cultural, em detrimento do econômico, é brilhantemente apontada pelo sociólogo Boaventura de Sousa Santos (1999) como um dos principais desafios da contemporaneidade. Esta visão é fruto de uma grande discussão dos diversos campos sociológicos que aponta a análise nesta direção, dos modos de vida em detrimentos dos modos de produção e assim por diante. Entretanto, numa breve análise do cenário e das agendas dos países, vemos que os principais problemas e questóes que envolvem os governos são de natureza econômica, tais como inflação, déficit, desemprego, dívida externa... Será então o foco correto? Será que a questão dos modos de produção e a estrutura da economia são tão passíveis de serem relegados a um segundo plano? Serão os sujeitos organizados e capacitados tão capazes de transformar todas as estruturas? A inadequação da proposta pode gerar diversos danos, como frustração da comunidade "atendida", cisões na comunidade, apropriação indevida ou expropriação dos espaços políticos de locução e ação no desenrolar da proposta.

Concordando com Guattari (2000), a questão não é se devemos ou não contribuir para a organização, se devemos ou não nos organizar, e sim se estamos ou não reproduzindo os modos de subjetivação dominante, e isso em qualquer uma de nossas ações cotidianas, inclusive de militância nas organizações. A organização pura e simples, o incremento dos chamados capitais sociais e humanos não garantem a negociação de um novo contrato social, podem sim passar a compor parte da estrutura que sustenta os atuais paradigmas, modos de subjetivação e sustentabilidade do status quo.

\section{A Vocação econômica do local é a base do incremento do capital econômico e estratégia contra-hegemônica da globalização excludente}

Há que se interpretar que as hipóteses sobre as quais esta premissa para o DS se assenta são: 
a) Todas as localidades possuem uma vocação econômica;

b) todas as localidades têm condições de competir no mercado, com o exercício de sua efetiva vocação e assim melhorar suas condições econômicas;

c) independentemente do modo de produção ou da forma pela qual esta vocação se exerce (visto que isto não é discutido ou sequer mencionado nos projetos, embora asseguremos exata discussão no Fórum, que ao analisar a "vocação", a avalia enquanto modo de produção passível de "improvement"), o incremento do capital econômico se dará de forma eqüitativa e conduzirá a ganhos de qualidade de vida na comunidade (fato que nunca ocorreu no mundo em 50 anos de grande incremento mundial de capital econômico).

Os fatos que, segundo nossa visão, corroem estas hipóteses estão relacionados às realidades dessas localidades e comunidades com baixo IDH, normalmente atendidas pelos projetos de DS, tais como:

- Possuir uma vocação pode ser uma realidade, entretanto, exercitar esta vocação de modo a competir no mercado global é uma hipótese inocente, talvez leviana e quiçá maquiavélica;

- a falta de estrutura para produção, distribuição e transporte impede, ou no mínimo dificulta em muito, a possibilidade de que qualquer um destes locais compita em "pé de igualdade" com localidades melhor servidas. Só funcionaria onde a vocação for o artesanato do "bom selvagem", o turismo, ou uma reedição das "plantations" tropicais;

- As únicas outras possibilidades de competir fundamentam-se no aviltamento absoluto dos salários (já patentes nas relações entre os gêneros e pontuais nos trabalhos com mão de obra infantil) e/ou na depredação radical do capital natural das localidades. $\mathrm{O}$ que acreditamos não ser a proposta dos que crêem no conceito de DS. Outro aspecto preocupante são as estruturas e modos de produção destas localidades, concentração dos meios de produção, principalmente terra e capital;

- A maior parte das localidades com baixo IDH tem por vocação a agricultura ou agropecuária, estes setores estão bastante reprimidos e globalizados, muitas de suas "comodities" encontram-se totalmente controladas por grandes holdings (limitando a possibilidade de lucros) e, cada vez mais, pela 
internacionalização do mercado, dependendo de vantagens comparativas e competitivas inatingíveis pelas pequenas comunidades. $\mathrm{O}$ associativismo e o cooperativismo, por maior potencial que tenham, são mais que uma bóia para que os pequenos proprietários de terra não se afoguem definitivamente. Os que não detêm meios de produção em qualquer escala estão irremediavelmente perdidos.

- Ao mesmo tempo em que o governo brasileiro comprometese, dentro de um programa como o Comunidade Ativa, a incentivar a vocação do município através do apoio à agenda de prioridades locais, observa-se que, apesar de a maioria dos municípios brasileiros terem por vocação a agropecuária, as estruturas federais (EMBRAPA, EMATER) e as regionais (CATI, EBDA...) destinadas a apoiar a agricultura têm sofrido uma considerável desestruturação, com baixos salários, redução de quadros, falta de estrutura logística e de apoio para o trabalho.

Qual a chance de obter real incremento de capital econômico? Qual a chance de que ocorra sem a subordinação cultural, social, econômica ou ambiental? Qual a chance de, em ocorrendo, não repetir os erros das estratégias de desenvolvimento centradas no capital econômico?

A própria comunidade se dá conta destas incongruências da proposta e se manifesta, ou então fica apenas com aquela sensação de que ainda não vai ser desta vez que algo vai mudar.

\section{Há que se otimizar o uso de recursos públicos através da organização local}

A altíssima demanda por bens e serviços públicos precisa ser direcionada e organizada; o Estado perde sua capacidade de implementar ações e deixa de ser mais e mais o Estado-providência. Como conciliar este fato com a realidade de desestrutura e desatendimento em todos os setores dos países não-desenvolvidos? Como poderão competir? Como poderão se desenvolver?

Certamente, a organização da demanda precisa ser feita, o desmonte do Estado é nítido. Outro ganho da proposta é evitar a apropriação político-partidária dos benefícios gerados com recursos públicos, apropriação de fato ou apropriação política do benefício. Existe, no entanto, uma dificuldade de compreensão do papel do 
Estado por parte da comunidade que, viciada em relaçôes convenientemente paternalistas com o poder público, tem noções equivocadas de direitos e deveres para com o mesmo. Há que se apontar, ainda, o risco para aumentar a passividade da sociedade civil frente a um desmonte mal planejado do aparelho do Estado; um novo contrato social, novas bases para a organização da sociedade devem partir desta e não do estado, a criticidade da sociedade civil é essencial para que as novas bases sobre as quais se assentarão a organização do Estadosociedade sejam realmente novas e não uma simples substituição do Estado pela sociedade e pelo mercado.

\section{Desafios metodológicos quanto à transformação política}

\section{Neste programa, o Planejamento participativo é realmente uma estratégia politica de transformação da sociedade, ou apenas uma estratégia técnica?}

No Brasil há um enorme fosso entre a sociedade civil e o Estado. A proposta política é, ou seria, aumentar o controle democrático do Estado pela sociedade civil através da participação organizada para se estabelecer ações, procedimentos e regras de convívio dos atores sociais e instituições. O fundamento das bases do novo contrato social parte, inexoravelmente, da premissa do direito de ser (direito de ser o que se é). Neste quadro, a estratégia educacional, técnica e comunicativa seria o estabelecimento de processos e espaços de negociação permanente, nas quais o convívio tenha suas regras definidas de modo efetivamente participativo. A estratégia política seria a constituição de redes de sustentabilidade da participação. No limite da utopia a sociedade civil inteira se constitui numa rede compactada que substitui o próprio Estado (Tassara, 2001). Para a "Comissão Independente População e Qualidade de Vida" o mundo mudou muito desde a formulação do Contrato Social de Rousseau; a liberdade natural e direito ilimitado transformaram-se, nesses duzentos anos, em superconsumo e hegemonia econômica de países e grupos econômicos. Um novo contrato social deve readequar a cidadania individual, a soberania nacional e a ordem mundial à realidade e sua construção fundamentase na participação de todos, indistintamente, na procura atuante de uma qualidade de vida melhor e sustentável. Para Ianni (1995), os dilemas do contrato social estão novamente recolocados, apenas com uma nova forma, decorrente das atuais condiçōes sociais, econômicas, políticas e culturais na sociedade global, condições nas quais o indivíduo se constitui e desenvolve. 
Propostas políticas nesta direção implicam em estratégias de planejamento participativo que partem, então, das seguintes hipóteses:

1) É possível a constituição de sujeitos coletivos.

2) O sujeito coletivo é, ou pode ser, a expressão de uma comunidade.

3) Das expressões do sujeito coletivo depreende-se um universo semântico, um discurso.

4) A depreensão dos argumentos por trás dos discursos/falas permite a análise e reflexão desideologizada.

5) O sujeito coletivo é um sujeito planejador.

6) A noção de planejamento para este sujeito coletivo deve ser sempre contínua, dinâmica e em um processo ininterrupto de construção/avaliação.

Sob estas hipóteses, o papel dos técnicos é o agenciamento de enunciaçôes (Guattari, 2000), é contribuir para a desideologização do espaço de locução, para o desmonte dos discursos, para a emergência do sujeito coletivo. O moderador deve constituir uma vanguarda que se auto-anula, que se afasta gradativamente (Tassara, 2001), que se percebe como um outsider, disposto a contribuir, a doar-se enquanto técnico, mas tendo a clara noção de sua limitação diante da grandiosidade deste encontro.

Assim, analisando a proposta política, depreendendo suas hipóteses que condicionam a metodologia, as técnicas, podemos efetivamente perceber uma proposta de trabalho.

O programa não discutiu, durante os processos de formação dos técnicos, os pressupostos políticos da metodologia na qual fomos treinados. A inserção consciente da técnica no contexto social, histórico e político ficou, assim, obra e arte de cada equipe técnica.

\section{Desideologização do espaço de locução}

Um grande desafio metodológico a ser destacado é a desinstrumentalização dos preconceitos, os enfrentamentos políticos entre grupos, entre zona rural e sede, entre gêneros, raças, diferentes níveis de escolaridade. Para Habermas (1968), um espaço de locução desideologizado propicia o desejo irresistível da consciência, da emancipação política. Para criar, construir com o grupo o clima pedagógico que permita o desmonte de argumentos para que estes se enfrentem, e não 
discursos, e ideologias que em geral são autoritários e divisores. Segundo o mesmo autor, as modificações do marco institucional dão-se por modelos de adaptação passiva ou ativa. $\mathrm{O}$ entendimento da transformação da sociedade como tarefa técnica é um equívoco dos tecnocratas planificadores capitalistas e do socialismo burocrático. Para Habermas, a racionalização ao nível do marco institucional só ocorre pela interação linguisticamente mediada, pela destruição das restriçôes da comunicação, sem coaçôes sobre adequações de princípios e normas orientadores das açôes. $\mathrm{O}$ decrescente grau de repressividade e rigidez possibilita aos membros da sociedade maiores oportunidades de emancipação e progressiva individuação. Numa situação que deve ser buscada permanentemente de um modelo de ação comunicativa pura, a distinção entre verdadeiro e falso consenso dar-se-ia automaticamente (Freitag \& Rouanet, 1993).

A emergência do sujeito coletivo depende de que os membros possam perceber suas origens comuns, sua partilha de universo semântico, de certezas e, assim sendo, sua partilha de destino. O que parece simples na teoria é um agenciamento complexo na prática, até mesmo porque os sentimentos de grupo não se constroem com a simples mobilização de pessoas, agrupamento de subgrupos e verbalizações didáticas da necessidade do coletivo, mas a partir de um trabalho lento e minucioso, capaz de compreender as limitaçóes de cada um, de demonstrar o significado de estar junto, de sensibilizar-se com as histórias pessoais inseridas em um coletivo, de trabalhar as nuanças das redes de aliança e redes de rejeição (Enriquez, 1997), de valorizar o encontro e buscar o significado da parceria na construção da visão de futuro comum.

Um indivíduo só se torna sujeito quando se percebe como tal e assume a posição de agente transformador da própria realidade. $\mathrm{O}$ processo de subjetivação é a transformação - parcial - do indivíduo em sujeito e pode ser entendida como o contrário da submissão deste a valores transcendentes; é ele que se torna o fundamento dos valores que orientam a construção da realidade. O sujeito empurra o indivíduo ou o grupo para a busca da liberdade, pela luta contra a ordem estabelecida e o determinismo social. O uso da razão é também instrumento da liberdade; ela só é negativa à medida que esta racionalização é dominada e usada pelas classes dominantes que dela se servem para impor seu poder àqueles que desta forma se transformam em instrumentos de produção e consumo, ou indivíduos não sujeitos, não atores. $\mathrm{O}$ sujeito só existe como momento social, como contestação 
da lógica da ordem, tome esta uma forma utilitarista ou simplesmente a busca da integração social (Tourraine, 1994).

\section{A integração da sociedade civil e poder público como base para o desenvolvimento integrado}

É claro que a integração das diferentes esferas do poder público (federal, estadual ou municipal) à sociedade civil é essencial. Mas como integrar sem atentar às relações político-econômicas estabelecidas historicamente? Este item não pretende que a discussão descambe para uma reedição do materialismo histórico marxista, mas tem por objetivo relembrar que o socialismo foi derrotado, mas o capitalismo não venceu, na medida em que esta questão não foi equacionada e continua, sim, sendo um dos fatores que condicionam o sub-desenvolvimento nos níveis locais e globais, dentro do município, dentro do estado, dentro do país e/ou dentre países.

Como parte de alguns processos de DLIS, percebemos que:

1) Os espaços de discussão e planejamento participativo não se constituem de modo integrado e realmente representativo, estando quase sempre comprometidos com o poder público local;

2) os espaços de locução e ação criados sem a adequada representatividade e sem aprofundar questōes referentes à estrutura político-econômica local ficam fragilizados e podem se tornar espaços político-partidários que não comportam divergências e oposiçôes em suas discussões internas;

3) a existência de processos de personalização do poder local, de um certo fisiologismo, presente na grande parte dos municípios trabalhados pelo projeto, representa um dos grandes entraves no processo de compreensão da proposta de DLIS, deixando a comunidade descrente de todo e qualquer discurso que envolva o poder local e resistente a propostas que busquem uma adesão/ parceria com estes núcleos de poder;

4) muitas vezes fragilizado, o grupo, ou espaço, termina por se desagregar na eleição seguinte, quando as divergências ocultas manifestam-se mais claramente e o interesse coletivo é apenas o retrato de interesses vinculados às relaçôes de poder do local;

5) o grupo ou espaço político sem a adequada representatividade não obtém o respeito da população, comprometendo a possibilidade 
de um trabalho voltado para a "escuta" da coletividade e contradizendo toda a essência do conceito de participação comunitária.

6) dificuldades e as demandas por capacitação para formação de conselhos, estabelecimento de redes, articulação inter-institucional, gestão de fóruns e conselhos, desenvolvimento de capilaridade de representações, orçamento participativo, projetos políticopedagógicos, planejamento rural coletivo (por microbacias, por assentamento, por comunidade rural).

\section{Desafios metodológicos quanto ao ambiente}

O processo de capacitação para o planejamento participativo do desenvolvimento local integrado e sustentável, entendido como um processo educacional, precisa ser reconhecido ainda como um processo de educação ambiental. A contextualização das reflexōes não garante a atenção às questões ambientais e corre-se então o risco de encontrarmos caminhos que, apesar de minimizar a degradação social, não respondam à necessidade de melhorar, e não degradar, a qualidade ambiental como um aspecto essencial à qualidade de vida presente e garantia da manutenção dos direitos das futuras geraçôes locais e globais. Os processos de degradação social e ambiental são faces do mesmo modelo de desenvolvimento que se pretende superar. Parece claro que a busca não se restringe à construção de um novo modelo hegemônico, antes disso pretende-se a adequação local do caminho da busca pela maior qualidade de vida. A solidariedade que se quer fomentar através da organização, da co-responsabilidade e cidadania dos membros dos fóruns não pode referir-se apenas ao município, ela deve ser interespacial e intergeracional, perceber as implicaçōes das açōes além do espaço político e além do tempo biológico das pessoas presentes nas discussōes. A proposta de DLIs tem manifestado preocupações ambientais na conceituação, mas não tem encontrado procedimentos, se é que realmente intenciona, para discutir o atual modelo com maior profundidade, que abarque realmente todas as suas implicações sociais e ambientais.

\section{Conclusões}

Este texto pautou-se na análise da proposta do trabalho de capacitação, na abordagem metodológica utilizada pela equipe responsável pelo trabalho e na avaliação do trabalho a partir de um arcabouço 
teórico que discute os limites e possibilidades do processo de construção do DS. Dessa forma, podemos elencar alguns elementos fundamentais para a nossa discussão, entendida como processo inacabado e, assim, em permanente construção, para tanto uma melhor intervenção educacional deve atentar-se aos seguintes aspectos:

1) Compreender o processo de Capacitação de grupos, fóruns e conselhos locais para além da dimensão técnica. Esta deve estimulá-los a se perceber como intelectuais no sentido gramsciano, capazes de inserir a técnica no seu contexto socialpolítico-histórico-cultural e de desenvolver uma capacidade de olhar a própria realidade sob um ângulo novo, despido das ideologias e preconceitos condicionados pela realidade.

2) Evitar a conteudização, a catequese e a reprodução de conceitos na prática educacional. Esta prática deve ser construída "simplesmente" a partir de uma carta de princípios dos técnicos em torno da participação, cidadania, emancipação e organização comunitária para a qualidade de vida e sustentabilidade. Dessa forma, os conceitos e valores vão sendo construídos pelo sujeito coletivo, que reelabora seus argumentos a partir destes.

3) Garantir uma proposta de encaminhamento por parte da Universidade ao trabalho de Capacitação, com o objetivo de observar e apoiar o percurso do Fórum sem, no entanto, intervir no seu caminhar autônomo.

4) Concentrar esforços na desconstrução, através do entendimento, dos processos produtores de ausência material que imputam um conceito hegemônico de desenvolvimento, fundamentado no consumo e produção. Esta desconstrução pelo entendimento dá-se através do resgate de valores locais e da redução das carências materiais-simbólicas por meio da mitigação destas carências por formas menos dilapidadoras e frustrantes.

5) Desvincular, na prática, a proposta política do programa governamental que passa a ser compreendido como uma dentre outras oportunidades de fortalecimento das estratégias locais. 6) Assegurar a rede de informaçōes entre os membros do próprio Fórum, evitando a centralização das ações e posições hierárquicas dentro do grupo (evitando também desgaste e sobrecarga de indivíduos, assim como sombreamento das ações 
que podem inclusive gerar um processo segregador e competitivo).

6) Fortalecer o potencial de formação de redes entre municípios, entre seus setores, entre seus conselhos e entre suas instituições. Com isso podemos contribuir para a formação de Redes de Sustentabilidade da Participação Locais/Regionais: que podem cumprir o papel de articular para romper com limites comuns (como estrutura produtiva, de transporte, comunicação...) e fomentar o sentimento de que há uma conspiração por este novo contrato social, por esta sociedade melhor que combate a sensação de impotência em relação à estrutura.

7) Assegurar a concretização de ações pequenas e "domésticas", capazes de dar visibilidade ao trabalho do Fórum e confiança no seu poder de transformação e realização.

8) E, por fim, acreditar que um novo contrato social não deverá se constituir a partir da substituição do Estado pelo mercado e pela sociedade civil numa grande bacanal de nome terceiro setor, mas sim por meio de processos educacionais e políticos que insiram todos na reflexão, ação e construção das bases sobre as quais se assentarão a sociedade civil e o Estado. A organização da sociedade civil através do planejamento participativo deve ser uma estratégia política para esta construção, nunca uma simples técnica de planejamento.

Sabemos que, ao levantarmos tais questionamentos e/ou sugestões, poderíamos reiniciar a construção de um novo texto. Por ora, podemos concluir, no entanto, que ao trabalhar com educação, $o$ caminho da dúvida pode nos proporcionar muitos acertos, basta compreendermos a prática como um processo ininterrupto de construção de conhecimento, desde que procedamos a avaliaçóes permanentes dos processos.

Recebido em dezembro de 2001 e aprovado em fevereiro de 2002.

\section{Notas}

1. Segundo a proposta, este momento requer também a participação e apoio de instituições outras (EBDA, SEBRAE, FLEM...) que deveriam estar presentes, através de seus técnicos, durante todo ou parte do processo de Capacitação. Nossa experiência tem mostrado que 
nem sempre esta participação ocorre, embora tenhamos constatado que, quando existe uma boa atuação de certos órgãos no local, a exemplo da EBDA, as chances da construção de um bom trabalho são maiores.

2. Uma melhor discussão na questão da Representatividade do local será feita adiante no texto.

3. Nordestear é uma licença poética dos autores que pretende colocar em pauta a questão do referencial Norte do verbo nortear que, apesar de sua origem no norte magnético para a orientação de caminhos, permite que discutamos as questôes da relação Norte-Sul, Nordeste-Sudeste.

4. Avaliamos, por exemplo, que o uso de transparências e intermináveis discursos expositivos sobre tais conceitos seriam, no mínimo, uma atitude pedagógica equivocada para o contexto do Fórum local.

\section{Referências bibliográficas}

BOSI, E. Memória e sociedade: lembranças de velhos. São Paulo: EDUSP, 1987. 402p.

COMISSÃO INDEPENDENTE POPULAÇÃO QUALIDADE DE VIDA. Cuidar do futuro: um programa radical para viver melhor, org. por M.L. Pintasilgo. Rio de Janeiro: Trinova, 1998. 389p.

CUNHA, A.S Uma avaliação da sustentabilidade da agricultura nos cerrados. Brasília, DF: IPEA, 1994. 256p.

ENRIQUEZ, E. Como estudar as organizações locais. In: FISCHER, T. (Org.). Gestão contemporânea: cidades estratégicas e organizaçôes locais. Rio de Janeiro: FGV, 1997.

FRANCO, A. Porque precisamos de DLIS? 2. ed. Brasília, DF: Instituto de Política; Millennium, 2000. 116p.

FREITAG, B.; ROUANET, S.P. Habermas. São Paulo: Ática, 1993. 216p. (Grandes cientistas sociais, 15)

GIROUX, H. Cruzando as fronteiras do discurso educacional: novas políticas em educação. Porto Alegre: Artes Médicas, 1999.

GUATARRI, F.; ROLNIK, S. Micropolitica: cartografia do desejo. 6. ed. Rio de Janeiro: Vozes, 2000.

HABERMAS, J. Técnica e ciência como "ideologia". Lisboa: Edições 70, 1968. 147p. (Biblioteca de filosofia contemporânea, 3).

IANNI, O. A sociedade global. 3. ed. Rio de Janeiro: Civilização Brasileira, 1995. 194p. 
KRENAK, A. Informação pessoal: treinamento Cohort 9; programa LEAD (Leadership for Environment and Development). São Paulo, ago. 2000.

MATUI, J. Construtivismo: teoria construtivista sócio-histórica aplicada ao ensino. São Paulo: Moderna, 1995.

SANTOS, B. S. Pela mão de Alice: o social e o político na pósmodernidade. São Paulo: Cortez, 2000.

TASSARA, E. Comunicação pessoal no curso de pós-graduação em "Educação Ambiental para a Sustentabilidade". Feira de Santana: Universidade Estadual de Feira de Santana, 2001.

TOURRAINE, A. Crítica da modernidade. 4. ed. Petrópolis: Vozes, 1994.

TRIGO, E.; KAIMOWITZ, D.; FLORES, R. Bases para uma agenda de trabalho visando o desenvolvimento agropecuário sustentável. Estudos Econômicos, São Paulo, v. 24, p. 31-97, 1994. Número especial.

VIEZZER, M. (Org.). Tratado de educação ambiental para sociedades sustentáveis e responsabilidade global. Rio de Janeiro: Grupo de trabalho das Ongs Rio-92, 1992. 8p. 